истема независимой оценки (подтверждения) соответствия парфюмерно-косметической продукции в Российской Федерации

\author{
Н.П. Петрова, А.В. Резайкина, С.В. Ротанов
}

ФГБУ «Государственный научный центр дерматовенерологии и косметологии» Минздрава России 107076, Москва, ул. Короленко, д. 3, стр. 6

\footnotetext{
Цель. Анализ результативности проведения комплекса мероприятий по оценке безопасности испытуемых образцов парфююмерно-косметической продукции и качества проводимых клинико-лабораторных исследований на примере испытательного центра ФГБУ «ГНЦДК» Минздрава России.

Материал и методы. При оценке безопасности испытуемых образцов парфюмерно-косметической продукции использовалось определение микробиологических, фризико-химических, токсикологических и клинических показателей. Рассмотрены результаты исследований образцов парфюмерно-косметической продукции общим количеством около 80 тыс. проб, поступивших в ИЦ ФГБУ «ГНЦДК» в период с 2012 по ноябрь 2015 г. Результаты и заключение. Проведенная статистическая обработка по всем видам исследований позволяет сделать вывод о стабильности объема испытаний в ИЦ ФГБУ «ГНЦДК» за период 2012-2015 гг. При анализе количества отдельных видов испытаний отмечается отсутствие отрицательной динамики выполненных исследований, что не исключает вариативность частоты использования каждого метода. Динамика выполнения проводимых испытаний отражает востребованность и результативность деятельности центра на рынке услуг.

Ключевые слова: парфюмерно-косметическая продукция, технический регламент ТС, испытательная лаборатория, показатель безопасности, токсикологический показатель.
}

Контактная инсформация: petrova.natasha.p@gmail.com. Вестник дерматологии и венерологии 2015; (6): 90—96.

\title{
C \\ System of independent evaluation (confirmation) of correspondence of perfumes and cosmetics in the Russian Federation
}

\author{
N.P. Petrova, A.V. Rezaikina, S.V. Rotanov
}

State Research Center of Dermatovenereology and Cosmetology, Ministry of Healthcare of the Russian Federation Korolenko str., 3, bldg 6, Moscow, 107076, Russia

Purpose. Efficiency analysis of measures to determine the safety of samples of perfumes and cosmetics and quality of clinical and laboratory studies conducted by the test centre FGU "GNTSDK" under Ministry of Medicine, RF.

Materials and methods. When evaluating the safety of tested samples of perfumes and cosmetics microbiological, physical and chemical, toxicological and clinical identification criteria were used. Investigation results of the samples were studied representing a total of about 80 thousand samples delivered to the ITS "GNTSDK" between 2012 and November 2015. Results and conclusion. Statistical processing of all kinds of studies makes it possible to arrive at a conclusion about the stability of tested volume at ITS "GNTSDK" within the period of 2012 - 2015. The analysis of certain types of tests shows the absence of negative dynamics of studies made which does not exclude a certain variation of frequency of using each method. The dynamics of conducting tests reflects the relevancy and efficiency of the centre activities in the service market. Key words: perfumes and cosmetics, technical regulations (the Customs Union), test laboratory, safety indicator, toxicological indicator.

Corresponding author: petrova.natasha.p@gmail.com. Vestnik Dermatologii i Venerologii 2015; 6: 90_96. 
С 1 июля 2012 г. на основании решения комиссии Таможенного союза от 23 сентября 2011 г. № 799 в Российской Федерации для осуществления контроля безопасности существует система оценки (подтверждения) соответствия парфюмерно-косметической продукции (ПКП) требованиям технического регламента Таможенного союза «О безопасности парфюмерно-косметической продукции» - ТР ТС 009/2011 [1]. Вступивший в силу с 01.07.2014 Федеральный закон № 412-ФЗ от 28.12.2013 «Об аккредитации в национальной системе аккредитации» по сути обеспечил создание системы государственного контроля качества лабораторных исследований для оценки ПКП, выпускаемой в обращение на территории государств - членов ТС в потребительской таре.

Лабораторные исследования по определению показателей безопасности и эфффективности (потребительских свойств) разнообразной ПКП проводятся в испытательных лабораторных центрах (ИЛЦ), подтверждение компетентности которых происходит в сроки, предусмотренные законом № 412-Ф3 от 28.12.2013 «Об аккредитации в национальной системе аккредитации», и находит отражение в реестре аккредитованных лиц Росаккредитации [2].

Лабораторные исследования ПКП должны выполняться аккредитованными испытательными лабораториями по определенной последовательности, что обусловлено методическими особенностями и требованиями безопасного проведения испытаний, а также экономической целесообразностью [3], предусматривающей следующий алгоритм:

изучение и анализ сопроводительной документации и маркировки образцов ПКП;

контроль микробиологической чистоты представленных образцов ПКП (посевы изучаемого материала проводят исключительно из упакованных образцов, не подвергавшихся вскрытию или внешнему воздействию);

определение фризико-химических показателей: водородного показателя и содержания токсичных элементов, свинца, мышьяка, ртути;

п определение токсикологических показателей при воздействии на живые системы;

- определение раздражающего и сенсибилизирующего действия при пробном применении по назначению волонтерами;

- определение клинических показателей средств гигиены полости рта: определение деминерализирующего действия образцов ПКП на эмаль зубов.

Получение достоверных и убедительных результатов на каждом из последующих этапов исследований образцов ПКП, свидетельствующих об их опасности для здоровья и/или недоброкачественности, является основанием для завершения исследований и выдачи соответствующего заключения [4].
Образцы ПКП в ИЛЦ могут поступать от предприятий-производителей, органов по сертификации, организаций - поставщиков косметических средств из-за рубежа и в целях судебной экспертизы. Заказчики сами выбирают испытательные лаборатории в зависимости от видов выполняемых ими исследований, места их расположения либо по сложившемуся порядку в течение многих лет. Заказчик свое задание для ИЛЦ оформляет в виде заявки. Заявка является документом, отражающим тесное и творческое взаимодействие ИЛЦ с заявителем, в связи с этим в ней излагаются все рабочие записи: номер и дата регистрации заявки, дата выдачи готовых протоколов, коды образцов, номера и даты протоколов, роспись получателя протоколов, причина отказа (при наличии), причина временной приостановки испытания (при наличии), сведения о предоставленных образцах (наименование компании, предоставляющей образцы, инфрормация об утилизации образцов), другие записи, необходимые в процессе работы с образцами. Запись «М, Ф-Х, Т - НД» делается в тех случаях, когда испытания проводятся только для определения клинико-лабораторных показателей и заявителями были представлены копии протоколов исследований микробиологических (М), фризико-химических (Ф-Х) и токсикологических (Т) показателей до начала исследований по определению клинико-лабораторных показателей и они не отличаются от показателей, изложенных в нормативных документах (НД). Запись «М, Ф-Х - НД» делается в тех случаях, когда микробиологические и физико-химические показатели не отличаются от показателей, изложенных в нормативных документах.

Между заказчиком и ИЛЦ заключается договор о проведении испытаний, проводится передача образцов, которые затем идентифицируются, кодируются, направляются на отдельные виды исследований либо на комплекс лабораторных тестов в соответствии с заданием заказчика. После получения в ИЛЦ результатов исследования заказчику работ выдается протокол испытаний, который отражает результаты по показателям, требуемым ТР. Указанный протокол предоставляется в орган по сертификации для получения декларации о соответствии или в органы Роспотребнадзора для государственной регистрации (если ПКП входит в список Приложения 12 ТР ТС 009/2011 [1]). Декларация и свидетельство о государственной регистрации позволяют свободно реализовывать ПКП на территории стран Евразийского экономического союза.

Целью настоящей работы явился анализ результативности проведения комплекса мероприятий по оценке безопасности испытуемых образцов ПКП и качества проводимых клинико-лабораторных исследований на примере испытательного центра (ИЦ) ФГБУ «ГНЦДК» Минздрава России. 


\section{Материал и методы}

Нормативно-техническая документация, регламентирующая деятельность ИЦ ФГБУ «ГНЦДК», в том числе технический регламент Таможенного союза «О безопасности парфюмерно-косметической продукции» ТР ТС 009/2011, Федеральный закон № 412-Ф3 «Об аккредитации в национальной системе аккредитации», методические рекомендации 01.038-08 «Экспресс-метод токсиколого-гигиенической оценки парфюмерно-косметической продукции с помощью люминесцентного бактериального теста», методические указания 4.2.801-99 «Методы микробиологического контроля парфюмерно-косметической продукции», СанПиН 1.2.681-97 «Гигиенические требования к производству и безопасности парфюмерно-косметической продукции".

При оценке безопасности испытуемых образцов ПКП использовалось определение таких параметров, как:

- физико-химические показатели и токсичные элементы: определение содержания свинца, мышьяка, ртути и водородного показателя;

микробиологические показатели: культуральные методы определения общего микробного числа, обнаружения мезофильных аэробных и анаэробных микроорганизмов, Candida albicans, Escherichia coli, Staphylococcus aureus, Pseudomonas aeruginosa;

ш токсикологические показатели определяются на биологических моделях с использованием лабораторных животных или альтернативными методами с определением общетоксического действия in vitro;

клинические (клинико-лабораторные) показатели: определение раздражающего и сенсибилизирующего действия с участием добровольцев с информированного их согласия.

В работе рассмотрены результаты исследований образцов ПКП общим количеством около 80 тыс. проб, поступивших в ИЦ ФГБУ «ГНЦДК» в период с 2012 по ноябрь 2015 г. включительно. Результаты подвергнуты статистической обработке с помощью программы Exel.

\section{Результаты и обсуждение}

Согласно данным Федеральной службы по аккредитации (Росаккредитации) из электронного источника Национальной части Единого реестра органов по сертификации и испытательных лабораторий (центров) Таможенного союза, в РФ существует 345 испытательных лабораторий (центров) и 118 органов по сертификации (ОС), осуществляющих исследования и оценку соответствия ПКП требованиям ТР ТС 009/2011. Из них в Москве и Московской области функционируют 262 ИЦ и 79 ОС соответственно [2]. Каждый из представленных в реестре ИЦ осуществляет деятельность в соответствии с областью аккредитации.

Исходя из данных реестра [2], не во всех этих центрах проходят испытания по всем пяти существующим методам исследований: фризико-химические, токсич- ные элементы, микробиологические, токсикологические, клинико-лабораторные.

Деятельность ИЦ ФГБУ «ГНЦДК» является правомерной, подтверждающей свою компетенцию аттестатом аккредитации и прохождением регулярных процедур подтверждения компетенции. Деятельность ИЦ отражена в уставе ФГБУ «ГНЦДК», структура ИЦ и исследователи показателей безопасности и потребительских свойств ПКП определены приказами директора ФГБУ «ГНЦДК». В ИЦ функционирует система менеджмента качества, и в деятельности центра соблюдаются требования менеджмента качества, установленные в руководстве по качеству в соответствии с пунктом 23 критериев аккредитации (приказ Минэкономразвития России №326 от 30.05.2014). ИЦ имеет средства измерения, испытательное и вспомогательное оборудование для проведения таких видов исследований, как определение содержания токсичных элементов, фризико-химических, микробиологических, токсикологических и клинических показателей. В настоящее время подготавливаются условия для расширения области аккредитации.

За период работы ИЦ с 2012 г. по настоящее время в соответствии с договорами, заключенными между ИЦ ФГБУ «ГНЦДК» и заказчиками работ, общее количество исследованных образцов ПКП по всем видам испытаний составило: на 2012 г. - 17 998, 2013 г. 21 302, 2014 г. - 18 596, 2015 г., включительно по ноябрь, - 22642 образца (см. таблицу).

Из представленных в таблице сведений следует, что за последние 4 года при определении токсикологических показателей стали отдавать предпочтение методу оценки in vitro в отличие от методов in vivo, что можно наблюдать по резкой кривой роста и спада данных показателей (рис. 1). Это обстоятельство связано с запретом на проведение испытаний на животных в Европе. Седьмая поправка к директиве Евросоюза ЕЭС 76/768/EЕС (Cosmetics Directive) [4] ввела положение по гуманному отношению к испытаниям на теплокровных животных. Этот документ определил юридическое требование к маркировке 26 конкретных ингредиентов в определенных пороговых концентрациях, независимо от функции вещества и его источника [5]. Кроме того, с 2004 г. соблюдение директивы запрещает испытания на животных для готовых ПКП и с 2009 г. - для ингредиентов в косметических средствах [6]. Однако данная поправка не запрещает компаниям-производителям проводить испытания на животных в лабораториях, расположенных в других странах, не входящих в Евросоюз.

В связи с этим по этическим принципам с учетом высокой стоимости эксперименты in vivo в испытательных лабораториях заменяют более доступные методы in vitro, вследствие чего биологические эксперименты проводятся с использованием альтернативных моделей, адаптированных для оценки ПКП. 
Таблица Данные о видах лабораторных испытаний, выполнявшихся на образцах ПКП в ИЦ ФГБУ «ГНЦДК» в период с 2012 по ноябрь 2015 г.

\begin{tabular}{|c|c|c|c|c|}
\hline Показатели & 2012 г. & 2013 г. & 2014 г. & 2015 г. (до 11.15) \\
\hline Токсикологические показатели (in vivo) & 3604 & 767 & 7 & 0 \\
\hline Токсикологические показатели (in vitro) & 810 & 5252 & 4702 & 5506 \\
\hline Физико-химические показатели & 2571 & 147 & 240 & 9 \\
\hline Определение водородного показателя рH & 0 & 2645 & 3329 & 3745 \\
\hline Определение содержания токсичных элементов & 142 & 2948 & 2657 & 4069 \\
\hline Клинические показатели & 7539 & 6802 & 4198 & 6003 \\
\hline Микробиологические показатели & 3332 & 2741 & 3463 & 3310 \\
\hline Итого & 17998 & 21302 & 18596 & 22642 \\
\hline
\end{tabular}

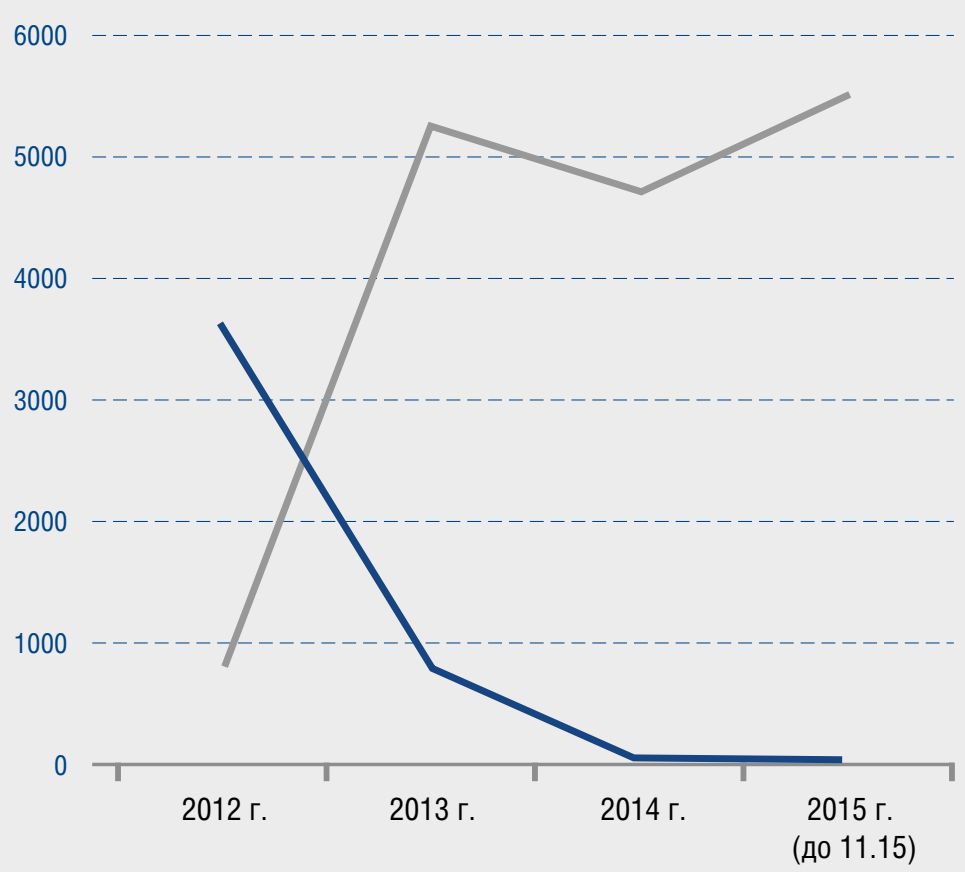
Токсикологические показатели (in vivo)
Токсикологические показатели (in vitro)

Рис. 1. Количество токсикологических показателей in vivo и in vitro, выполнявшихся с образцами ПКП в ИЦ ФГБУ «ГНЦДК» в период с 2012 по ноябрь 2015 г.

В ИЦ ФГБУ «ГНЦДК» для оценки токсикологического показателя применяется экспресс-метод токсикологогигиенической оценки ПКП с помощью люминесцентного бактериального теста [7-9].
В ИЦ ФГБУ «ГНЦДК» до 2013 г. безопасность ПКП оценивалась с учетом комплекса физико-химических показателей в соответствии с ГОСТами $[10,11]$ для каждого вида продукции. Кроме определения водо- 


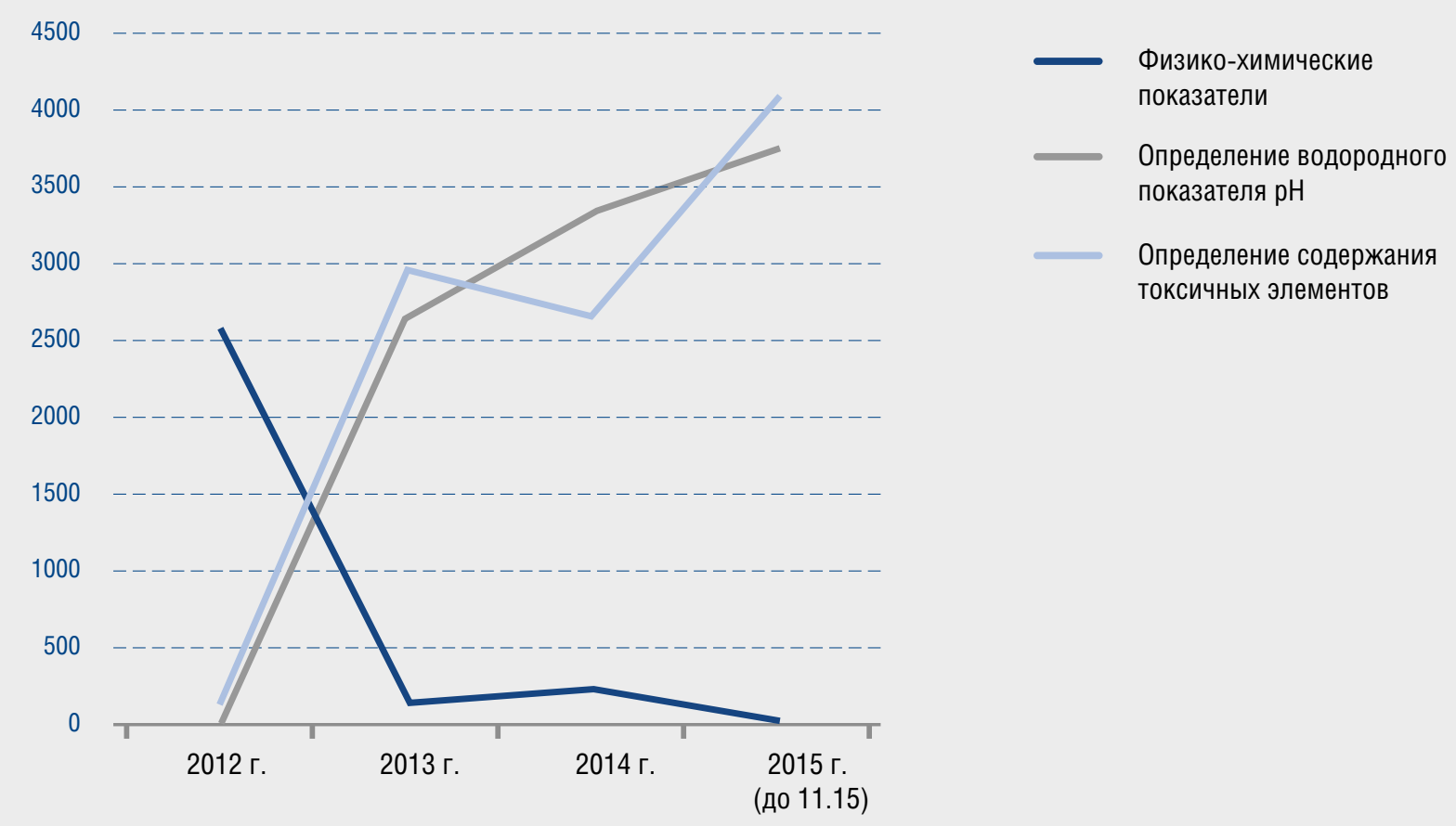

Рис. 2. Количество комплекса фризико-химических показателей, водородного показателя и определение содержания токсичных элементов: свинца, мышьяка, ртути, выполнявшихся на образцах ПКП в ИЦ ФГБУ «ГНЦДК» в период с 2012 по ноябрь 2015 г.

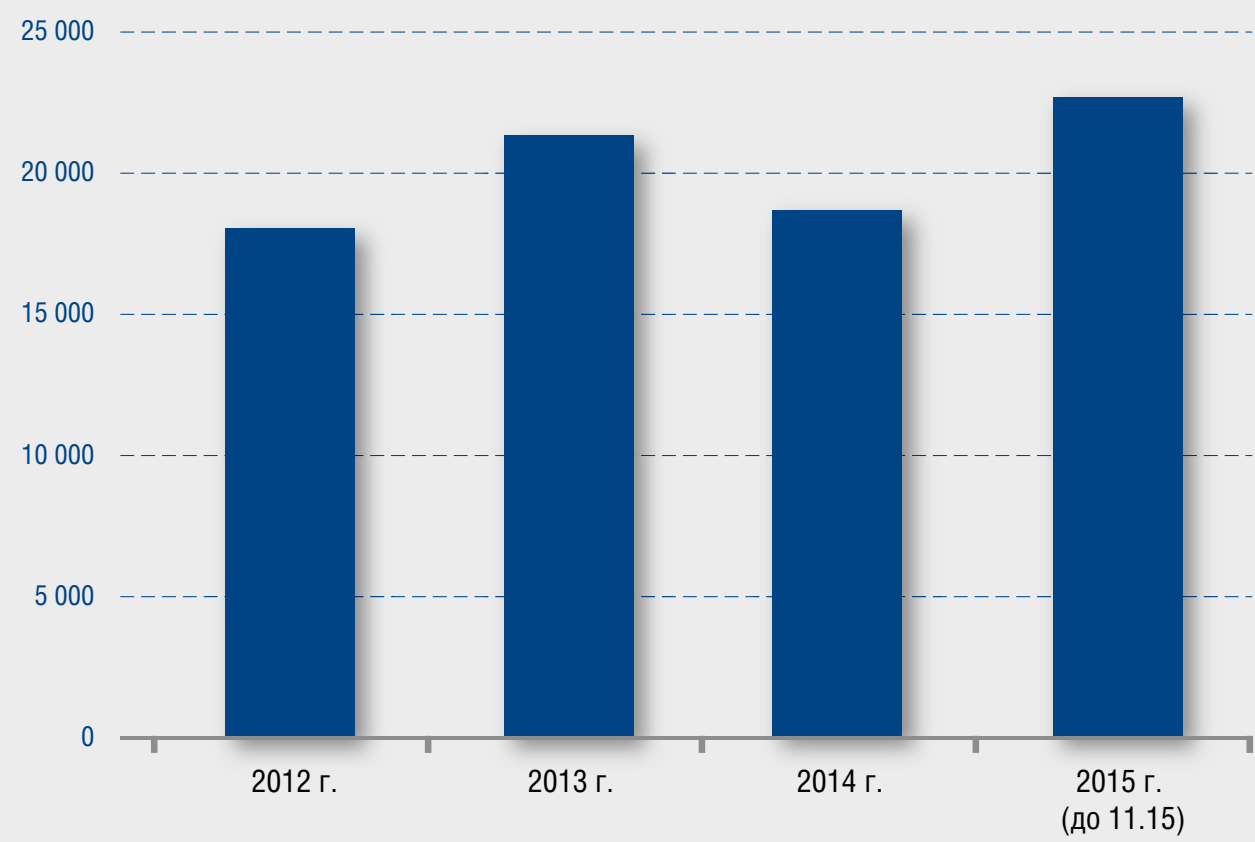

Рис. 3. Общее количество всех видов исследований ПКП, выполнявшихся в ИЦ ФГБУ «ГНЦДК» в период с 2012 по ноябрь 2015 г. 
родного показателя исследовались коллоидная стабильность, термостабильность, пенное число, массовая доля хлоридов и т.д. Согласно решению коллегии ЕЭК № 42 от 12.03.2014 «О внесении изменений в Перечень стандартов, содержащих правила и методы исследований (испытаний) и измерений, в том числе правила отбора образцов, необходимые для применения и исполнения требований ТР ТС 009/2011 и осуществления оценки (подтверждения) соответствия продукции» [12] ТР был упрощен для комплекса физико-химических показателей, вследствие чего определение содержания токсичных элементов (свинца, мышьяка, ртути) и водородного показателя требуется не для всех видов ПКП. Материалы, представленные в таблице по данным показателям, нашли свое отражение на рис. 2.

Данные объема выполненных исследований по микробиологическим и клиническим показателям остаются приблизительно на одном уровне, различия объема работ за временной период 2012-2015 гг. составляет $\pm 10 \%$.

Таким образом, в результате проведенной статистической обработки по всем видам исследований прослеживается стабильность объема испытаний в ИЦ ФГБУ «ГНЦДК» за последние четыре года (рис. 3). При анализе количества отдельных видов испытаний отмечается отсутствие отрицательной динамики выполненных исследований, что не исключает вариативность частоты использования каждого метода.

Наличие таких методов испытаний, как исследование токсикологических и клинических показателей с привлечением базы добровольцев, также может обусловливать данную стабильность. В ИЦ ФГБУ «ГНЦДК» часто обращаются заказчики с просьбой провести повторные клинические испытания, потому что подобные испытания в других ИЦ, имеющих более слабый уровень материально-технического оснащения и методического обеспечения, дают неудовлетворительные ре- зультаты, ввиду чего мы можем судить о привлекательности деятельности ИЦ ФГБУ «ГНЦДК».

Анализ результатов исследований, проведенных в ИЦ ФГБУ «ГНЦДК» с 2012 по 2015 г., позволил прийти к заключению, что благодаря высокому уровню требований, производству входящего качественного контроля и выпускающего качественного контроля, на основании лабораторных исследований не было установлено значительных отклонений по токсикологическим, физико-химическим, клиническим и микробиологическим показателям либо они находились на пограничном уровне. Выявленные случаи единичных отклонений или получение показателей на пограничном уровне не составляют основную массу статистики.

\section{Заключение}

Система независимой оценки качества клиниколабораторных исследований, созданная Росаккредитацией, обеспечивает результативность проведения комплекса мероприятий по подтверждению безопасности ПКП и благополучно действует на территории РФ и стран - членов Евразийского экономического союза.

Одним из центров с достаточным материально-техническим оснащением и методическим обеспечением, подтверждающим свою компетенцию аттестатом аккредитации и другими мероприятиями в соответствии с Федеральным законом №412 «Об аккредитации в национальной системе аккредитации», является ИЦ ФГБУ «ГНЦДК» Минздрава России.

На примере ИЦ ФГБУ «ГНЦДК» была определена динамика выполнения проводимых исследований по разным показателям в период за 2012-2015 гг., которая отражает востребованность и результативность деятельности центра на рынке услуг.

Однако высокие требования менеджмента качества нацеливают на внедрение в ИЦ нового оборудования и современных методов тестирования с учетом рекомендаций межгосударственных и международных стандартов. І І

\section{Литература}

1. Technical Regulations of the Customs Union on the safety of perfumery and cosmetic products (TR CU 009/2011). [Технический регламент Таможенного союза «О безопасности парфюмерно-косметической продукции» (ТР ТС 009/2011).]

2. Register of accredited persons. Rosakkreditacija. [Реестр аккредитованных лиц. Росаккредитация. http://fsa.gov.ru/index/staticview/ id/297/ available на 11.2015.]

3. Filonjuk V.A. Hygienic assessment of perfume and cosmetic products and oral hygiene. Guidelines. Minsk: BGMU, 2007. [Филонюк В.A. Гигиеническая оценка парфюмерно-косметической продукции и средств гигиены полости рта. МР. Минск: БГМУ, 2007.]
4. EЭC 76/768/EEC (Cosmetics Directive) Directive 2003/15/EC of 27 February 2003 is the 7th amendment to the law.

5. Technical Guidance Document for the Determination of Fragrance Materials in Cosmetic Products, 2006. Cosmetics Europe, 2006.

6. Full EU ban on animal testing for cosmetics enters into force. European Commission. March, 2013.

7. Guidelines of express method of toxicological and hygienic assessment of perfumery and cosmetic products using the luminescent bacteria test Rospotrebnadzor Russia, 2008. [Методические рекомендации 01.038-08 Экспресс- метод токсиколого-гигиенической оценки парфюмерно-косметической продукции с помощью люминесцентного бактериального теста. Роспотребнадзор России, 2008.]

8. Gus'kova 0.A., Zav'jalov N.V, Skvorcova E.L. Evaluation of the toxicity of chemicals by using alternative methods Toksikologicheskij vestnik 2013; 6: 34-39. [Гуськова 0.А., Завьялов Н.В, Скворцова Е.Л. Оценка токсичности химической продукции с использованием альтернативных методов. Токсикологический вестник 2013; (6): 34-39.] 
9. Danilov V.S., Egorov N.S. Bacterial bioluminescence. M: MGU, 1985. [Данилов В.С., Егоров Н.С. Бактериальная биолюминесценция. М: Изд-во МГУ; 1985.]

10. State industry standard 52341-2005 Production of color cosmetics based on the emulsion. [ГОСТ P 52341-2005 Продукция декоративной косметики на эмульсионной основе.]
11. State industry standard $28767-90$ Products makeup fat-based. [ГОСТ 28767-90 Изделия декоративной косметики на жировой основе.]

12. Decision № 42 On Amendments to the List of standards containing rules and methods of researches and measurements, including the rules of sampling required for the application and enforcement of the TR CU "On the safety of perfumery and cosmetic products" and implementation of assessment of conformity 03/12/2014. [Peшeние № 420 внесении изменений в Перечень стандартов, содержащих правила и методы исследований и измерений, в том числе правила отбора образцов, необходимые для применения и исполнения требований ТР ТС «0 безопасности парфююмерно-косметической продукции» и осуществления оценки соответствия продукции 12.03.2014.]

об авторах:

Н.П. Петрова — исследователь токсикологических показателей испытательного центра ФГБУ «ГНЦДКК» Минздрава России, Москва

А.В. Резайкина - д.м.Н., просрессор, руководитель испытательного центра ФГБУ «ГНЦДК» Минздрава России, Москва

С.В. Ротанов — д.м.Н., доцент, врач лабораторного центра ФГБУ «ГНЦДК» Минздрава России, Москва

\section{Конфликт интересов}

Авторы заявляют об отсутствии потенциального конфлликта интересов, требующего раскрытия в данной статье 